\title{
Efektivitas Proses Pengambilan Serat Daun Nanas (Ananas Comosus Merr) Dengan Metode Pengeratan
}

\author{
Agus Hery Supadmi Irianti \\ Jurusan TI Fakultas Teknik UM
}

\begin{abstract}
Abstrak.Blitar merupakan penghasil nanas terbesar di Jawa Timur Pada musim panen dapat kita lihat limbah daun nanas yang menggunung.di lokasi pertanian nanas. yang menyebabkan polusi udara.. Setiap satu batang pohon nanas menghasilkan limbah antara $2-3 \mathrm{~kg}$, jika jarak tanam nanas adalah $1 \mathrm{~m}$ maka setiap $100 \mathrm{~m}$ tanah yang ditanami nanas dapat menghasilkan limbah 200 sampai $300 \mathrm{~kg}$ limbah dan untuk 1 hektar lahan akan mencapai 3 ton limbah. Jika ini dibiarkan maka dapat mengganggu lingkungan. Dari kenyataan ini peneliti ingin memanfaatkan limbah daun nanas dengan mengambil seratnya

Tujuan Penelitian ini untuk Mengetahui waktu yang diperlukan, jumlah produk yang dihasilkan serta kualitas dari proses memisahkan $1 \mathrm{~kg}$ limbah daun nanas dengan metode pengeratan. Selain itu tujuan lainnya adalah mengetahui metode pengambilan serat limbah daun nanas yang paling efektif dari berbagai metode.

Jenis penelitian ini adalah eksperimen tentang pengambilan serat limbah daun nanas dengan berbagai metode diantaranya metode pengeratan. Penelitian ini dilakukan di lapangan. Analisis data yang digunakan adalah analisis deskriptif. Sedangkan untuk mengetahui efektifitas metode yang digunakan dianalisis dengan Analisis One Way Anova

Hasil dari penelitian mengenai rata-rata waktu yang diperlukan untuk pengambilan serat dengan metode pengeratan dibutuhkan waktu 141,66 menit ( 2 jam 21 menit). Hasil produk serat yang dihasilkan untuk metode pengeratan diperoleh hasil 90 gram berat basah dan 33.33 berat kering. Kualitas warna serat yang diperoleh dengan metode pengeratan adalah krem
\end{abstract} kusam

Adapun Uji efektivitas waktu pengambilan serat menunjukkan terdapat perbedaan efektivitas waktu yang sangat nyata dimana $\mathrm{F}$ hitung $>\mathrm{F}$ tabel pada taraf $5 \%$, yaitu 1.2E+07 > 5,14. Hasil uji menunjukkan bahwa antara perendaman dan peragian tidak ada perbedaan efektivitas waktu ( $0.34<5.14)$, perendaman dan pengeratan terdapat perbedaan efektifitas waktu ( $9.8>5.14)$, peragian dan pengeratan terdapat perbedaan efektifitas waktu( 6497701,89>5.14) Adapun Uji efektivitas Berat yang dihasilkan menunjukkan bahwa terdapat perbedaan berat basah serat yang sangat nyata antara pengambilan serat dengan metode perendaman, peragian dan pengeratan, dimana $\mathrm{F}$ hitung $>\mathrm{F}$ tabel pada taraf $5 \%$. yaitu $81.750>5,14$. Hasil uji menunjukkan bahwa antara perendaman dan peragian ada perbedaan efektivitas berat serat basah ( $13.395>5.14)$, perendaman dan pengeratan ada perbedaan efektivitas berat serat basah ( 27.25>5.14), peragian dan pengeratan terdapat perbedaan efektifitas berat serat basah ( 26.25>5.14) dan untuk berat serat kering menunjukkan bahwa terdapat perbedaan berat kering serat yang sangat nyata antara pengambilan serat dengan metode perendaman, peragian 
dan pengeratan, dimana $\mathrm{F}$ hitung $>\mathrm{F}$ tabel pada taraf $5 \%$. yaitu $7.971>5,14$. Hasil uji menunjukkan bahwa antara perendaman dan peragian tidak ada perbedaan efektivitas berat serat basah $(2.096<5.14)$, perendaman dan pengeratan tidak ada perbedaan efektivitas berat serat basah $(1.7<5.14)$, peragian dan pengeratan terdapat perbedaan efektifitas berat serat basah ( $7.57>5.14)$

\section{Kata Kunci: efektivitas, serat nanas, Berbagai Metode}

\section{PENDAHULUAN}

Limbah merupakan masalah yang perlu mendapatkan perhatian khusus baik segi penanganannya maupun pemanfaatannya. Apabila masalah limbah tidak diatasi akan mengganggu dan membahayakan bagi lingkungan dan manusia itu sendiri. maka dari itu berbagai upaya untuk mengatasi limbah merupakan prioritas yang mendesak agar dapat mengambil langkah yang paling tepat dan bermanfaat bagi kepentingan orang banyak. Blitar merupakan penghasil nanas terbesar di Jawa Timur. Petani Nanas di daerah ini hanya dapat memanfaatkan buah nanas sebagai sumber penghasilan. Pada musim panen dapat kita lihat limbah daun nanas yang menggunung.di lokasi pertanian nanas. Setiap satu batang pohon nanas menghasilkan limbah antara 2-3 kg, jika jarak tanam nanas adalah $1 \mathrm{~m}$ maka setiap $100 \mathrm{~m}$ tanah yang ditanami nanas dapat menghasilkan limbah 200 sampai $300 \mathrm{~kg}$ limbah dan untuk 1 hektar lahan akan mencapai 3 ton limbah. Hal ini terjadi karena daun nanas tidak dapat dimanfaatkan untuk makanan ternak, jadi biasanya petani hanya membakar yang menyebabkan polusi udara karena asapnya serta ada yang membiarkan begitu saja. Penanganan limbah daun nanas dengan metode yang efektif dan efisien tentu akan memberikan nilai tambah tersendiri apabila dikaji dari sisi ekonomis., sehingga perlu diupayakan penanganan limbah .diantaranya pengambilan serat daun nanas dengan metode pengeratan

\section{PEMBAHASAN}

\section{A. Jenis Nanas}

Tanaman nanas dibudidayakan orang untuk diambil buahnya. Tanaman nanas yang nama latinnya Ananas Comosus Merr berasal dari Brasilia. Ada dua golongan tanaman nanas yang lazim di Indonesia, yaitu golongan cayenne dan Gueen (Santono, 1998:11). Di Blitar jenis nanas yang banyak ditanam adalah nanas Gueen. Adapun ciri nanas jenis gueen adalah berdaun pendek dan berduri tajam, buah berbentuk lonjong mirip kerucut sampai silindris, mata buah menonjol, berwarna krem sampai kemerah-merahan dan rasanya manis.

\section{B. Serat Daun Nanas dan Manfaatnya}

Selain buahnya, sebenarnya daun nanaspun secara teori memiliki serat yang kuat dan terindah yang dihasilkan oleh alam nabati (Heyne, 1980:507) . Di Pilipina daun nanas digunakan sebagai bahan baku textil. Akan tetapi di Indonesia limbah daun nanas ini belum dimanfaatkan secara maksimal (Atjung, 1976:40). Serat nanas dapat digunakan untuk interior dinding, karpet dan kursi (Nelwan Anwar, Kompas 30 Desember 2003). Selain dari itu serat nanas juga dapat digunakan sebagai bahan campuran untuk Batik sutera nanas. Batik Sutera Nanas berasal dari benang sutera 
dan serat daun nanas (Pantjer Budi Waluyo, Kompas, 2 Januari 2004) Produksi kain ini dikembangkan di daerah Pemalang Jawa Tengah.

\section{Metode Pengambilan Serat Limbah Daun Nanas}

Beberapa metode yang dapat dilakukan untuk mendapatkan seratnya. Ketiga metode untuk mengambil serat tersebut menurut Balai Besar Penelitian dan Pengembangan Industri Kerajinan dan Batik adalah dengan cara perendaman, peragian dan pengeratan (1991:14).

Cara perendaman adalah proses pengambilan serat daun nanas dengan cara direndam. Proses perendaman pada dasarnya adalah membusukkan daun nanas. Pada proses perendaman ini akan tumbuh bakteri yang akan mengurai jaringan daun nanas, sehingga yang tersisia hanya seratnya saja.

Sedangkan metode peragian adalah pengambilan serat dengan cara melayukan daun selama 2 hari kemudian direbus sampai lunak dengan titik didih $100^{\circ} \mathrm{C}$, ditiriskan ditata dan ditaburi ragi tape untuk mempercepat pembusukan dan dibiarkan selama 8 hari.

Metode pengeratan adalah proses pengambilan serat daun nanas dengan cara dikerat. Menggunakan pisau. Pengeratan ini untuk menghilangkan lapisan daun sehingga serat dengan mudah dapat dikeluarkan. Dari ketiga metode ini belum pernah dikaji lebih dalam mana yang paling efektif. Yang dimaksud efektif disini adalah lebih mudah, lebih cepat dan produk banyak.

Pembuatan assesories busana dari kertas serat daun nanas apabila ditinjau dari beberapa sisi memiliki beberapa hal yang sangat menguntungkan, karena selain dapat mengatasi limbah daun nanas paska panen, keberhasilan ini juga akan berdampak kepada masyarakat petani nanas. Petani nanas yang selama ini hanya memanfaatkan buahnya dapat juga memanfaatkan daunnya sebagai bahan baku kertas. Dari sisi wilayah Blitar juga memiliki tempat strategis yang banyak dikunjungi wisatawan, yaitu Makam Bung Karno. Sehingga penelitian ini sangat diperlukan karena dapat membantu petani nanas untuk mengelola limbah secara professional. Sehingga dapat memberikan nilai tambah bagi petani nanas.

Disisi lain kalau dicermati pengolahan limbah daun nanas menjadi serat merupakan produk yang berbau etnik, karena terbuat dari bahan alam yang ada di Indonesia. Apabila produk olahan limbah ini dikembangkan akan dapat membentuk pasar baru, seperti dikatakan Hasyim, Mustofa $\mathrm{H}$ dalam bukunya yang berjudul Membela Mengangkat Tekstil Tradisional, bahwa Pasar terbentuk oleh suatu arus permintaan, tetapi ada juga pasar yang sengaja dibentuk oleh promotornya, yang bekerjasama dengan media massa. Akan tetapi pada dasarnya peran produknya juga dapat membentuk pasar. (1998:62) Apabila ini ditekuni dengan dukungan tempat yang strategis yang telah dimiliki kota Blitar, maka akan dapat meningkatkan pendapatan petani nanas selain memanfaatkan buahnya. Tanaman ini merupakan herba perenial atau bienial, tinggi $50-150 \mathrm{~cm}$, daun memanjang seperti pedang dengantepi berduri maupun tidak berduri panjangnya $80-150 \mathrm{~cm}$. Kultivar utama nanas yang dibudidayakan di dunia adalah 'Smooth Cayenne', 'Red Spanish','Queen', dan 'Abacaxi' (Morton, 1987). Berbagai nama berbeda diberikan untuk tanaman ini antara lain pineapple (Inggris), ananas dan pina (Spanyol), nanas (Indonesia), dan abacaxi (Portugal) (CABI, 2003). Budi daya tanaman nanas di Indonesia pada umumnya berupa perkebunan rakyat dalam skala kecil dan perkebunan besar swasta. Daerahdaerah yang sudah lama dikenal sebagai produsen nanas adalah Sumatra Selatan, 
Lampung, Jawa Barat (Subang dan Bogor), dan Jawa Timur (Blitar). Peningkatan daya saing komoditas tanaman nanas dapat ditempuh dengan pemanfaatan tanaman yang selama ini belum dilakukan. Selain menghasilkan buah, tanaman ini juga membentuk akar, batang, dan daun. Selama ini daun belum dimanfaatkan secara optimal. Bagian ini biasanya hanya dibuang dan tidak memiliki nilai ekonomi, meskipun daun nanas mengandung serat yang dapat dimanfaatkan untuk bahan baku tekstil. Nanas mudah untuk dibudidayakan, bahan tanam yang biasa digunakan untuk perbanyakan adalah daun mahkota (crown), anakan (sucker), dan tunas samping (slip). Nanas mudah tumbuh pada curah hujan sekitar 1.000 - $1.500 \mathrm{~mm}$ per tahun, walaupun demikian dapat juga di daerah dengan curah hujan yang tinggi seperti di Bogor. Nanas merupakan tanaman xerofit dan termasuk dalam golongan Crassulacean Acid Metabolism (CAM) sehingga tanaman ini sangat tahan terhadap kondisi kekeringan (CABI,2003). Nanas ini memiliki umur panen yang tinggi dan memiliki harga yang rendah. Berikut ini adalah langkah mengambil serat dengan metode pengeratan:

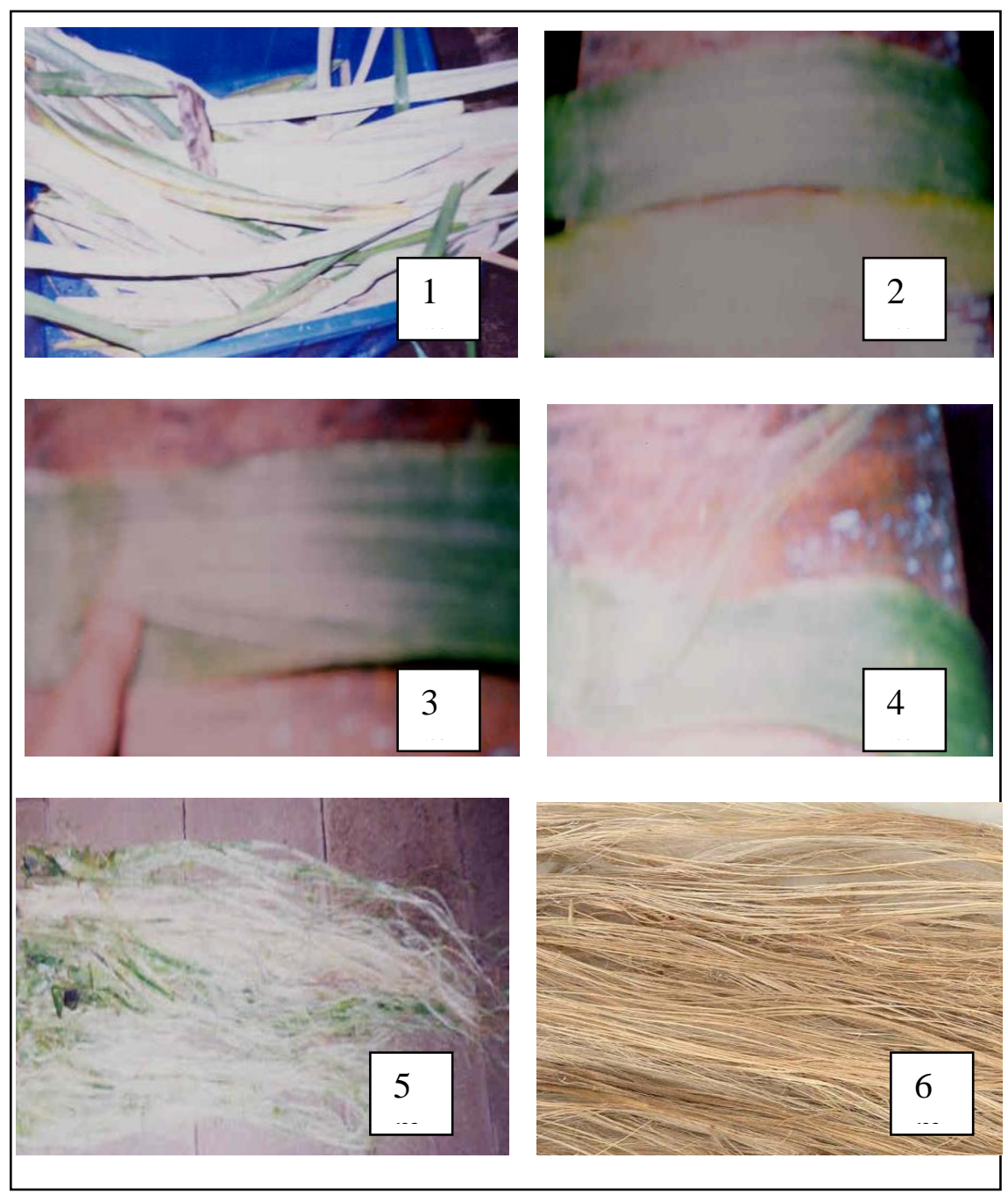

Gambar 1. Langkah pengeratan

Keterangan: 
1. Daun nenas yang sudah dibersihkan

2. Daun siap dikerat

3. Kerat sampai terlihat serat daun

4. Daun siap dipisahkan seratnya

5. Hasil Serat masih basah

6. Hasil jadi serat dengan metode pengeratan

\section{D.Ciri Serat Daun Nanas yang Baik}

Jenis serat ada dua macam yaitu serat alam dan serat buatan. Serat nanas merupakan jenis serat alam. Adapun salah satu ciri semua jenis serat adalah ukuran panjangnya yang relatif lebih besar dari lebarnya. (Tanpa Nama , 1984:1) Adapun ciri lain selain panjang serat adalah warna serat. Serat nanas yang baik berwarna crem cerah (Kompas, 2 Jan 2004).

\section{PERMASALAHAN}

Hasil pengamatan selama ini banyaknya limbah daun nanas di daerah Blitar. Pada musim panen hanya dibakar sehingga menyebabkan adanya polusi udara . Belum dimanfatkannya limbah daun nanas

\section{PEMECAHAN MASALAH}

Agar limbah daun nanas tidak mengganggu, maka perlu didayagunakan limbah daun nanas menjadi sesuatu yang bermanfaat serta dapat memberikan nilai tambah bagi petani nanas.Salah satu alternatif menangani limbah daun nanas adalah dengan mengambil serat daun nanas. Pengambilan serat limbah daun nanas dapat dilakukan dengan pengeratan

\section{METODE}

Pada penelitian ini digunakan metode eksperimen, populasi yang digunakan dalam penelitian ini adalah jenis limbah daun nanas. Teknik pengambilan sample dengan purposive sampling.

Pengujian dilakukan terhadap proses pengambilan serat limbah daun nanas dengan metode perendaman, peragian dan pengeratan. Parameter yang diuji adalah pengujian terhadap waktu pengambilan serat dengan berbagai metode, banyaknya serat yang dihasilkan dengan metode perendaman, peragian dan pengeratan. Serta kualitas serat dari berbagai metode. Pengujian dilakukan di laboratorium tata busana.Namun demikian dalam artikel ini hanya dilihat pada metode pengeratan saja.

Data yang diperoleh dianalisis menggunakan analisis deskriptif untuk mengetahui keefektifannya digunakan analisis anova satu jalur.

\section{PENUTUP}

Dari hasil penelitian yang disajikan dalam bab $\mathrm{V}$ dapat ditarik kesimpulan bahwa: Waktu rata-rata yang dibutuhkan pada proses pengambilan serat limbah daun nanas dengan metode pengeratan membutuhkan waktu 141, 66 menit (2 jam 21 menit) untuk setiap kilogram limbah daun nanas. Berat serat yang dihasilkan pada metode pengeratan berat basah 90 gram dan berat kering 33 gram. Semua berat ini diperoleh dari $1 \mathrm{~kg}$ limbah daun nanas. Kualitas serat dapat ditinjau dari warna, 
tekstur, tingkat kekusutan dan kekempalan setelah serat dalam kondisi kering. Warna yang ditimbulkan pada proses pengambilan serat dengan metode pengeratan krem kusam. Tekstur serat pada metode pengeratan agak kasar. Tingkat kekusutan serat pada metode pengeratan tidak terlihat kekempalan.

Hasil Uji efektivitas waktu yang digunakan ada perbedaan nyata efektivitas waktu yang digunakan untuk pengambilan serat dengan berbagai metode. Hasil uji menunjukkan bahwa antara perendaman dan peragian tidak ada perbedaan efektivitas waktu $(0.34<5.14)$, perendaman dan pengeratan terdapat perbedaan efektifitas waktu $(9.8>5.14)$, peragian dan pengeratan terdapat perbedaan efektifitas waktu ( $6497701,89>5.14)$

Hasil Uji efektivitas berat serat basah ada perbedaan nyata efektivitas berat serat basah dengan berbagai metode. Hasil uji menunjukkan bahwa antara perendaman dan peragian ada perbedaan efektivitas berat serat basah ( 13.395>5.14), perendaman dan pengeratan ada perbedaan efektivitas berat serat basah $(27.25>5.14)$, peragian dan pengeratan terdapat perbedaan efektifitas berat serat basah $(26.25>5.14)$

Hasil Uji efektivitas berat serat kering ada perbedaan nyata efektivitas berat serat kering dengan berbagai metode. Hasil uji menunjukkan bahwa antara perendaman dan peragian tidak ada perbedaan efektivitas berat serat basah $(2.096<5.14)$, perendaman dan pengeratan tidak ada perbedaan efektivitas berat serat basah $(1.7<5.14)$, peragian dan pengeratan terdapat perbedaan efektifitas berat serat basah $(7.57>5.14)$. Hasil penelitian adalah sebagai berikut:

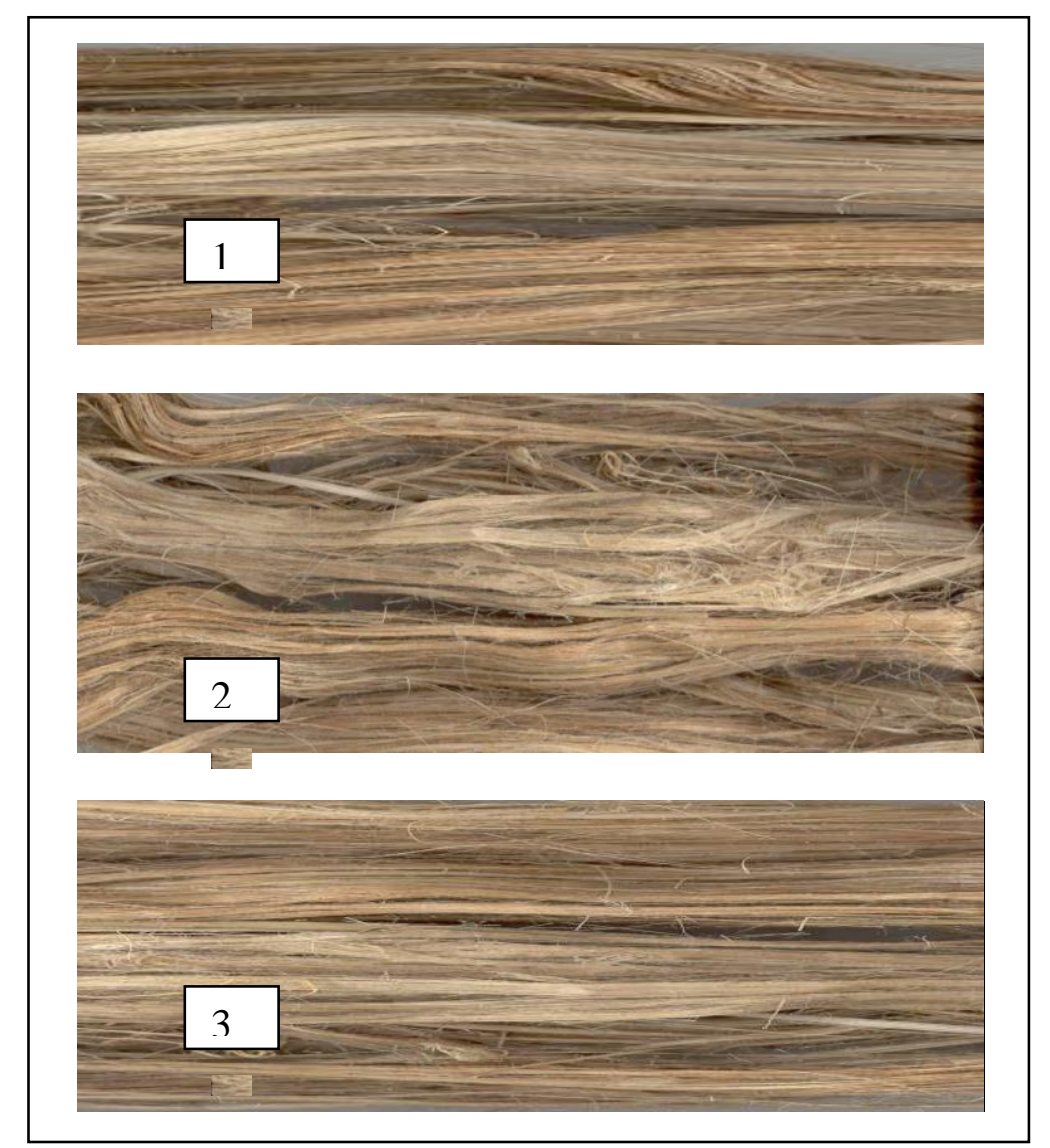

Gambar 2 Serat Hasil Metode Perendaman Replikasi 1,2 dan 3 


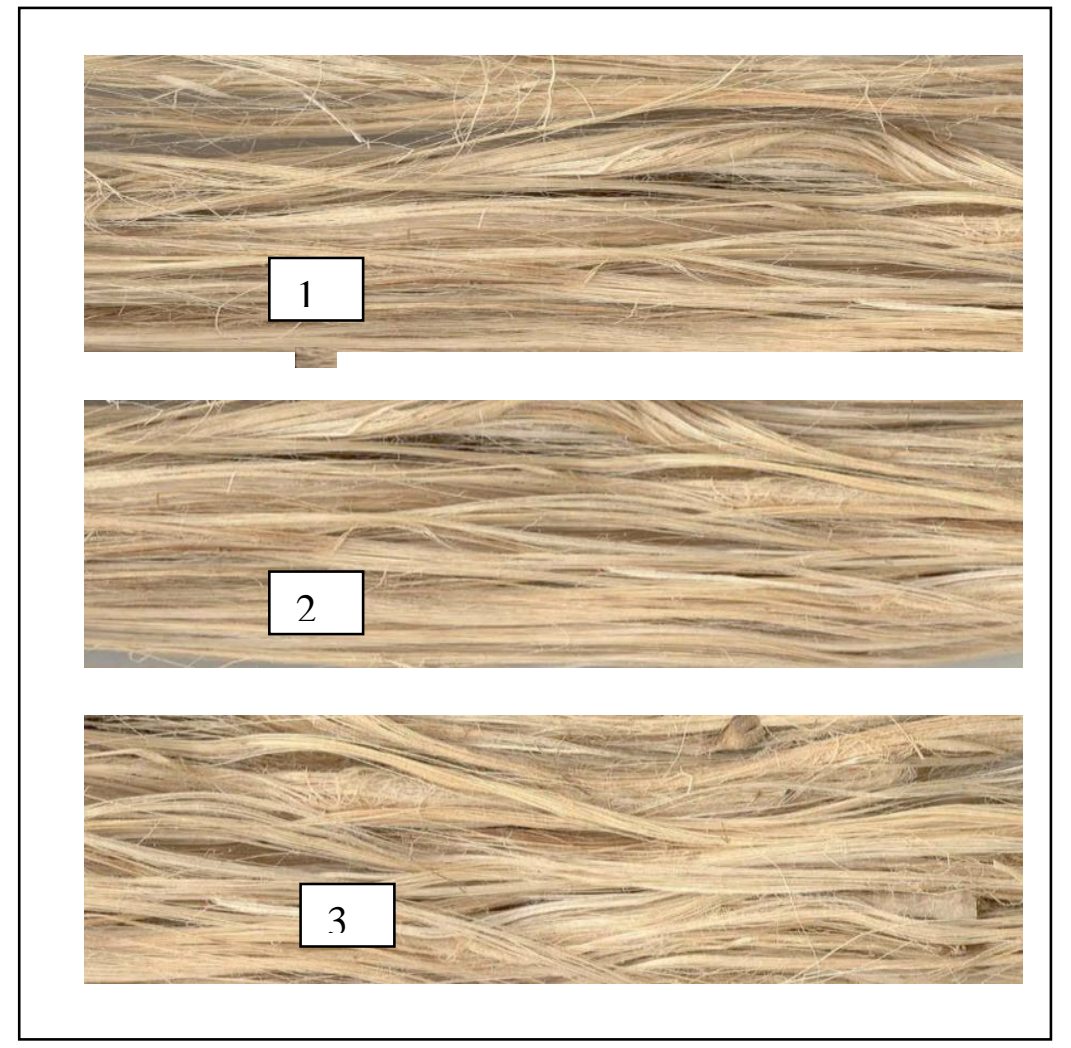

Gambar 3 Serat Hasil Metode Peragian Replikasi 1,2 dan 3
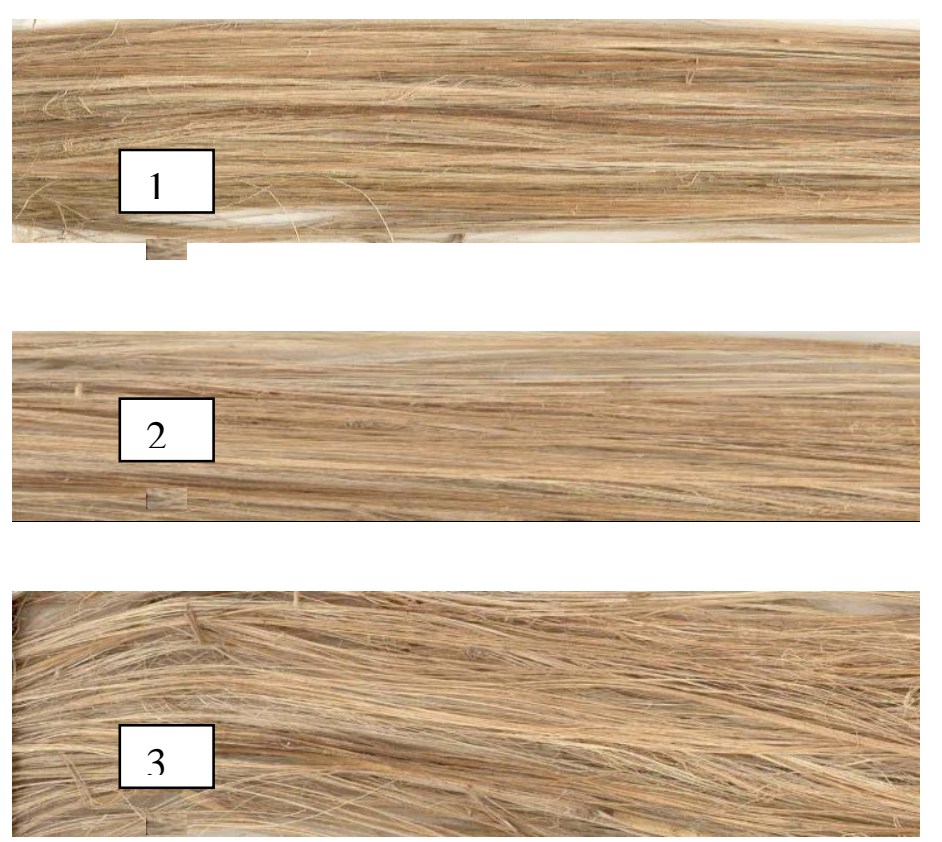

Gambar 4 Serat Hasil Metode Pengeratan Replikasi 1,2 dan 3 


\section{KEPUSTAKAAN}

Atjung. 1976. Tanaman Obat Indonesia. Jakarta: N.V Masa Baru.

Balai Besar Penelitian dan Pengembangan Industri Kerajinan dan Batik. 1991. Penelitian Proses Pemisahan Serat Batang Pisang Sebagai Bahan Baku Industri Tekstil Kerajinan. Yagyakarta: Departemen Perindustrian.

CABI (Centre for Agriculture and Bioscience International). 2003. Crop protection compendium. Wellingford,CABI

Hasyim Mustofa W. 1998. Membela, Mengangkat Tekstil Tradisional, Upaya di Tengah Laju Perkembangan Industri Tekstil. Yogyakarta: LP Yayasan PETTRI.

Heyne, K. 1993. Tumbuhan Berguna Indonesia. Jakarta: Yayasan Sarana Warna

Morton, J. 1987. Pineapple. In: fruits of warm climates. Julia F. Morton, Miami, FL p. 18 28. http://www. hort.purdue.edu/newcrop/morton/pineapple.html.

Nelwan, 30 Des 2003. Tenun Serat Nanas Digemari Perancang Busana Luar negeri. Kompas Hal 14

Tanpa Nama.. 1983. Serat Tekstil. Bandung: Institut Teknologi Tekstil

Waluyo Pantjer Budi. 2004. Batik Sutera Nanas Digemari karena Motifnya, Kompas 2 jan2004 Hal 8 


\section{BIODATA}

NAMA LENGKAP : DRA.AGUS HERY SI, M.PD

ALAMAT INSTANSI: JURUSAN TI FAK TEKNIK UNIV NEGERI MALANG

JL. SEMARANG 5 MALANG 65145

ALAMAT EMAIL : agushery_um52@yahoo.co.id

No Telphon : 081233594878. 


\section{SERTIFIKAT}

Nomor. 4205/H34.15/PM/2010

Diberikan kepada:

Dra. Agus Hery Supadmi Irianti, M.Pd.

\section{Scloagai PEMAKALAH}

deng'an judul

Efektivitas Proses Pengambilan Serat Daun Nanas

(Ananas Comosus Merr) Dengan Metode Pengeratan

Daliam Seminar Nasional (haurater Building for V'ocational Education timgral so Desember 2010)

di.Jurusan P'endidlikan Teknik Boga dan Busana FT LNY

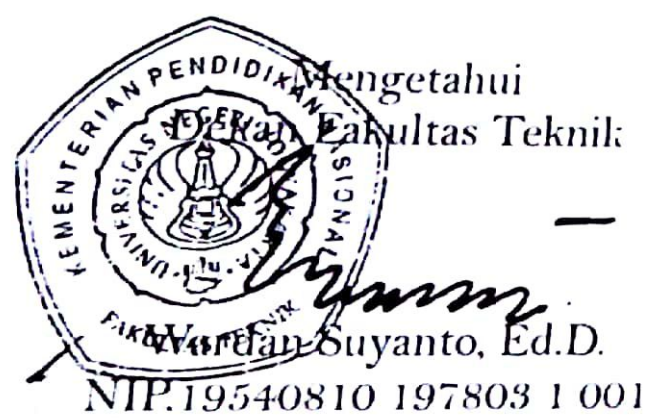

Yogyakarta, 5 Desember $\underline{010}$ Ketua Panitia Seminar Nasional PTBB

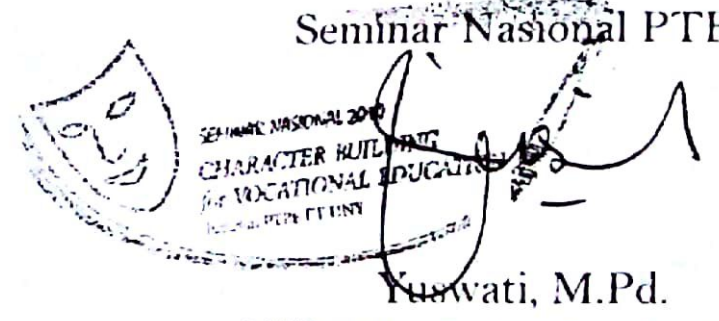

NIP.1954 0202+ 198303 g OOg 